Author(s):

Title:

A Systems Framework for Defining

Nonproliferation Program Technology Requirements

Submitted to:

Chad Olinger, NIS-7

Paul Argo, NIS-1

Jo Ann Howell, NIS-7

Mohini Rawool-Sullivan, NIS-6

Susan Voss, NIS-1

DOE Office of Scientific and Technical Information (OSTI)
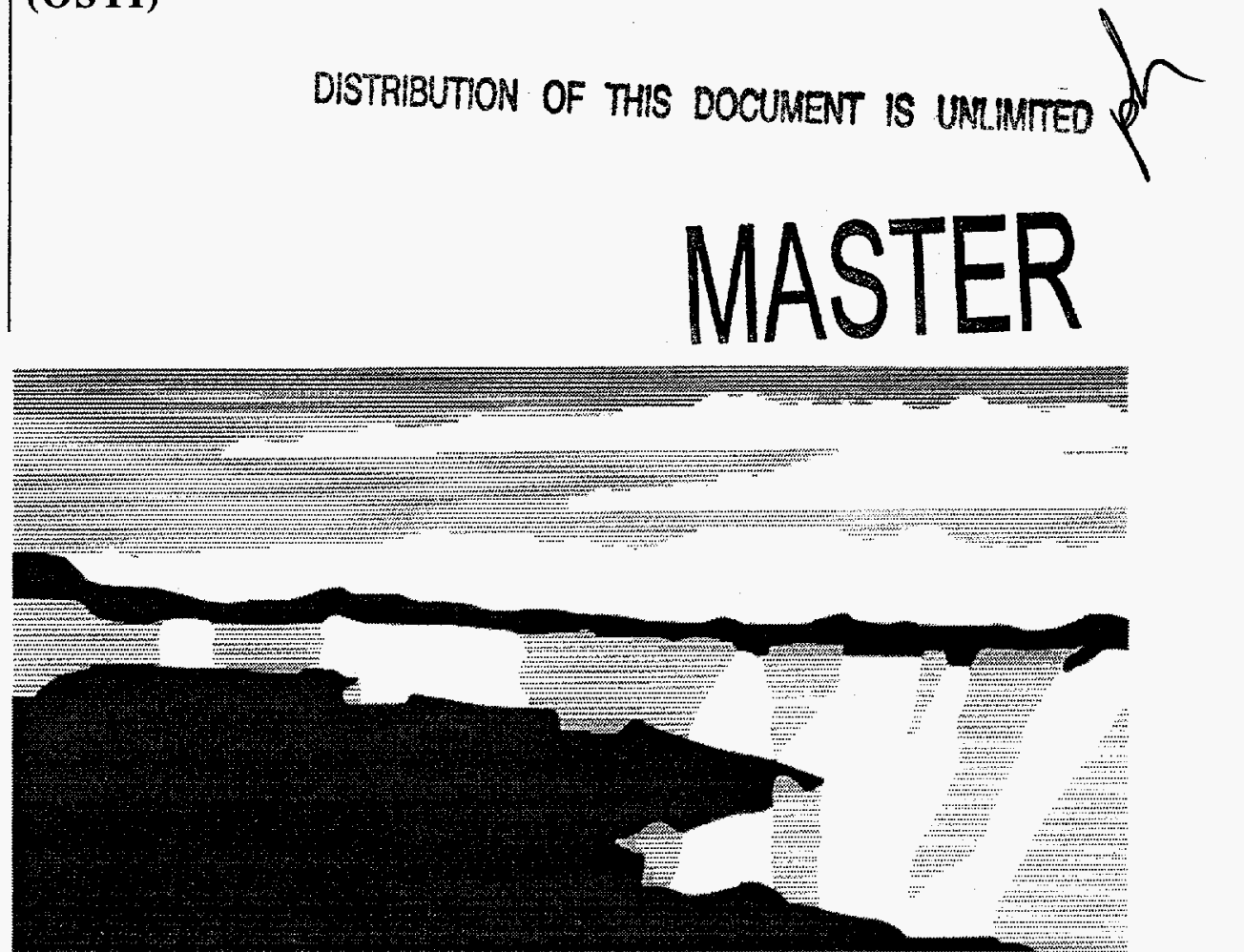

NATIONAL LABORATORY

Los Alamos National Laboratory, an affirmative action/equal opportunity employer, is operated by the University of California for the U.S. Department of Energy under contract W-7405-ENG-36. By acceptance of this article, the publisher recognizes that the U.S. Government retains a nonexclusive, royaltyfree license to publish or reproduce the published form of this contribution, or to allow others to do so, for U.S. Government purposes. The Los Alamos

National Laboratory requests that the publisher identify this article as work performed under the auspices of the U.S. Department of Energy. 


\section{DISCLAMER}

Portions of this document may be illegible in electronic image products. Images are produced from the best available original document. 


\section{DISCLAIMER}

This report was prepared as an account of work sponsored by an agency of the United States Government. Neither the United States Government nor any agency thereof, nor any of their employees, makes any warranty, express or implied, or assumes any legal liability or responsibility for the accuracy, completeness, or usefulness of any information, apparatus, product, or process disclosed, or represents that its use would not infringe privately owned rights. Reference herein to any specific commercial product, process, or service by trade name, trademark, manufacturer, or otherwise does not necessarily constitute or imply its endorsement, recommendation, or favoring by the United States Government or any agency thereof. The views and opinions of authors expressed herein do not necessarily state or reflect those of the United States Government or any agency thereof. 


\title{
A Systems Framework for Defining Nonproliferation Program Technology Requirements
}

Chad Olinger*, Paul Argo, Jo Ann Howell, Mohini Rawool-Sullivan, and Susan Voss

\begin{abstract}
This is the final report of a one-year, Laboratory-Directed Research and Development (LDRD) project at the Los Alamos National Laboratory (LANL). This systems analysis study provided a framework for evaluating the technology developments needed to support an emerging nonproliferation regime that provides for global fissile materials control. The project produced an integrated program plan describing areas for technology advancement and the supporting Los Alamos strengths.
\end{abstract}

\section{Background and Research Objectives}

Emerging U.S. nonproliferation initiatives will continue to focus on detecting diversion of declared material, detecting misuse of declared facilities, and detecting undeclared nuclear activities. Implementation details of these initiatives will impact existing institutions such as the International Atomic Energy Agency (IAEA) as well as domestic safeguards programs in sovereign countries. In this way, U.S. nonproliferation initiatives will become part of a larger global fissile materials control regime. Verification of such a control regime poses a daunting challenge in terms of the number and complexity of facilities that store and process these materials and the large amounts of material and their diverse forms. Traditional international safeguards technologies and procedures applied to this task would require large increases in inspection resources. Alternatively, new developments in nonproliferation technologies can reduce verification resource requirements while enabling expansion of safeguards into these new roles.

Needed innovations in technology to verify fissile material controls will depend on the nature of the implementing institutional arrangements, operational systems that are in place and can support safeguards, and the specific processing and storage facilities that are to be safeguarded. For example, future institutional arrangements could include traditional

* Principal investigator, e-mail: colinger@lanl.gov 
Nonproliferation Treaty (NPT) safeguards and regional or bilateral agreements; future facilities and materials could include current civilian fuel cycles, more advanced fuel cycles with new reactor designs, or other fissile material disposition options; excess weapons materials; or military fuel cycles (for example, a verified production cutoff). In addition, there is clearly a growing role for international inspections to detect undeclared facilities. Because international safeguards have not previously been applied within many of these contexts and are sometimes inconsistent with developing safeguards needs (for example, bilateral treaties for weapons dismantlement), new verification technologies are needed. Recently, Euratom worked closely with the IAEA in implementing new technologies to reduce the number of inspector-hours required per facility. This program was successfully implemented and could provide a model for increasing safeguards efficiency on a regional basis.

This LDRD project was designed to take a broad view of current and anticipated nonproliferation needs and identify existing programmatic capabilities at Los Alamos National Laboratory that can efficiently fulfill these needs. The intent of this work is to improve customer satisfaction by providing a framework within which new or expanding nonproliferation activities can be developed. The research objectives and goals of this project are to identify current or future nonproliferation needs where Los Alamos has a strong technical infrastructure. The first step in this process is to identify technical nonproliferation needs based on the global nonproliferation environment and existing U.S. policies. These are compared to existing or proposed capabilities at Los Alamos. Program opportunities are identified where Los Alamos has diverse technical capabilities that, when combined, meet multiple needs of nonproliferation policy.

\section{Importance to LANL's Science and Technology Base and National R\&D Needs}

The intent of this project was to focus nonproliferation-related R\&D efforts to meet developing policy needs. Rapid changes in the world's political environment over the past five years have provided opportunities to develop policies and treaties that would have been unthinkable ten to fifteen years ago. These new policies generate new challenges for technology development required to support current and future policy positions or treaty commitments.

Two benefits can come from identifying how current and potential nonproliferation activities at Los Alamos address high-level domestic and international policy needs. First, researchers at Los Alamos can better understand the longer-range application goals of nonproliferation technologies and capabilities we develop. Helping researchers understand the 
policy context in which their technical capabilities are being developed should improve the final product.

Second, in many cases technical capabilities at Los Alamos support multiple policy initiatives for our customers, particularly in the nonproliferation arena. Identifying synergy among different, but related, projects helps Los Alamos in demonstrating its programmatic efficiency. This project supports a Los Alamos core competency in analysis and assessment.

\section{Scientific Approach and Results to Date}

The nonproliferation setting has changed significantly over the past five years. In an effort to optimize investment of nonproliferation support and $R \& D$ efforts we have examined the current nonproliferation setting from a systems perspective. In this systems framework we viewed the political events such as domestic restructuring, international treaties, bilateral agreements, and unilateral initiatives as establishing policy requirements. These events, in conjunction with the existing nonproliferation environment, result in global safeguards and nonproliferation requirements. Political and institutional settings establish constraints for implementing technical solutions. Enabling technologies were then identified and developed that meet the systems needs. This systems framework is shown schematically in Figure 1.

In the process of this work we have identified individual treaties and policies that directly impact nonproliferation and arms control. These, in conjunction with changes in the global nonproliferation environment - the break-up of the former Soviet Union (FSU), apparent proliferation attempts in Iraq and North Korea (both NPT member states), possible future break-up of China, growing global demand for nuclear energy, and disposition of fissile material from warhead dismantlement - place growing demands on nonproliferation efforts that diverge from historical safeguards applications and nonproliferation efforts (deterrence and safeguards based on verification of declarations).

Some information on the treaties has been entered into a prototype database that, if completed, could be used to identify related technological requirements among different treaties. Project proposals that support multiple customers in this way might benefit from cooperative funding from multiple customers. Recent changes in the global nonproliferation environment have been documented.

As part of this project we also developed a listing of current and proposed nonproliferation projects at Los Alamos. Work compiled by the Nonproliferation Program Office for the DOE comprised the vast majority of this listing at first, but we have added technologies developed outside of Los Alamos programs that could be applicable to nonproliferation. 
Having studied a large number of the relevant treaties, the nonproliferation environment, and LANL technical capabilities, we identified a small number of program development opportunities that tap multiple capabilities within LANL and address developing needs of customers. Beyond identifying these possible program development opportunities, we also supported a workshop on continuous unattended remote monitoring. This workshop was held September 19 and 21, 1995, to further develop an understanding of customer needs and define unique capabilities at LANL to address this technology that cuts across multiple program areas and addresses needs of multiple nonproliferation customers.

\section{Publications}

Bryan Fearey, Chad Olinger, Joseph Pilat, Jack Marking, Donald Close, Debra Rutherford, and William Stanbro, "Option Evaluation for Placing Classified Weapon-Components and Weapon-Materials Under International Safeguards," LA-MS Report LA-13022 (1995).

Chad Olinger, and Susan Voss, "A Systems Framework for Nonproliferation Research and Development," in Proceedings of the 36th Annual Meeting of the Institute for Nuclear Material Management, XXIV, in press (1995), Los Alamos Report LA-UR 95-2333 (1995). 


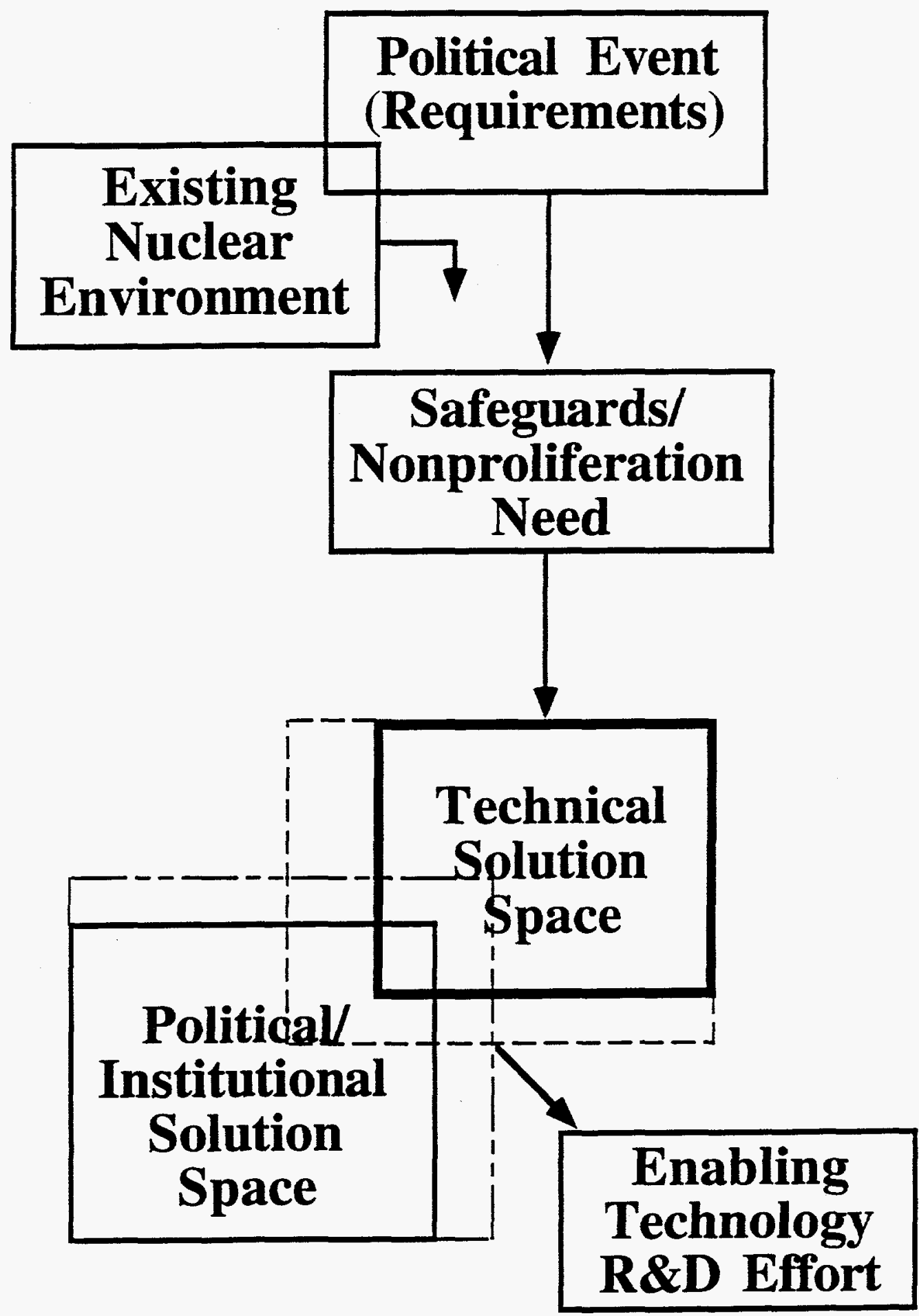

Figure 1. Development of a systems framework for nonproliferation R\&D. The overlapping portions of the possible technical and political/institutional solutions represent areas where effort should be directed. 